\title{
大丽轮枝菌毒素对棉花悬浮细胞 $\mathrm{NO}$ 和 $\mathrm{H}_{2} \mathrm{O}_{2}$ 的产生和 GST 基因表达的影响
}

\author{
贾芝琪 袁海永 李颖章* \\ (中国农业大学生物学院, 植物生理学与生物化学国家重点实验室, 北京 100094. * 联系人, E-mail: livingzhang@cau.edu.cn)
}

\begin{abstract}
摘要 一氧化氮 $(\mathrm{NO})$ 和过氧化氢 $\left(\mathrm{H}_{2} \mathrm{O}_{2}\right)$ 是重要的信号分子, 参与调控植物的各种生理过程, 特别是在

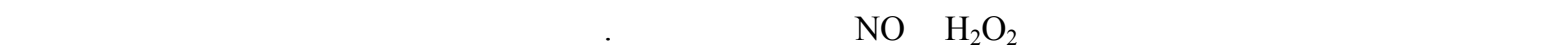
(VD-toxins)的抗性反应以及其对GST基因表达的调控作用. 结果表明, $\mathrm{NO}$ 和 $\mathrm{H}_{2} \mathrm{O}_{2}$ 信号参与棉花细胞抗 大丽轮枝菌毒素的信号途径，从而诱导抗性反应. $\mathrm{NO}$ 和 $\mathrm{H}_{2} \mathrm{O}_{2}$ 信号可能协同作用，但不相互依赖. GST基 因在棉花悬浮细胞抗大丽轮枝菌毒素抗性反应中起重要作用. NO对GST基因表达的调控不依赖 $\mathrm{H}_{2} \mathrm{O}_{2}$, $\mathrm{H}_{2} \mathrm{O}_{2}$ 对GST基因表达的诱导作用更强.
\end{abstract}

关键词 一氧化氮 过氧化氢 大丽轮枝菌毒素 棉花悬浮细胞 $G S T$ 基因

棉花黄萎病是由大丽轮枝菌(Verticillium dahliae $\mathrm{K})$ 真菌侵染引起的, 对棉花品质和产量都有严重危 害. 病原菌侵染能引起棉花细胞生成如植保素等多 种物质, 结构上也发生如维管束堵塞等的变化 ${ }^{[1]}$. 病 原菌或病原菌衍生的激发子或毒素侵染可活化抗病 基因表达 ${ }^{[2 \sim 6]}$, 产生抗菌化合物, 如PR蛋白和木质素 [7 10]. 我们最近的研究结果证明, 大丽轮枝菌分泌的 毒素可诱导拟南芥悬浮细胞细胞骨架和细胞核仁发 生改变 ${ }^{[11]}$. 然而, 目前对棉花细胞防卫反应的分子 基础了解较少, 抗性的遗传决定因子还需进一步阐 明.

有研究显示, 植物细胞与病原菌或病原菌衍生 的激发子相互作用能诱发 $\mathrm{H}_{2} \mathrm{O}_{2}$ 的产生, $\mathrm{H}_{2} \mathrm{O}_{2}$ 的产生 是植物细胞对病原菌或激发子最早的反应之一. $\mathrm{H}_{2} \mathrm{O}_{2}$ 作为信号的中间体，在植物防卫反应中调节基因表 达和程序性细胞死亡 ${ }^{[12 ~ 17]}$. Desikan等人 ${ }^{[18]}$ 的研究显 示, $\mathrm{H}_{2} \mathrm{O}_{2}$ 至少可以促进或抑制 175 个拟南芥基因的表 达, 表明在胁迫反应中, $\mathrm{H}_{2} \mathrm{O}_{2}$ 具有多种作用.

NO也已被证明是一个调节植物防卫基因活化的 必需分子 [19 26]. 已经证实, NO协同活性氧(ROS)刺激 寄主细胞死亡 ${ }^{[23,27,28]}$, 激活HR (hypersensitive reaction)反应 ${ }^{[29,30]}$. NO的产生对HR反应的启始和发展起 重要作用, 抑制NO的产生可增加对病原菌侵染的敏 感性 ${ }^{[31]}$. $\mathrm{NO}$ 和 $\mathrm{H}_{2} \mathrm{O}_{2}$ 可单独也可协同作用, 调节基因 表达 ${ }^{[32]}$.
我们在以前的研究中已经证实, $\mathrm{NO}$ 和 $\mathrm{H}_{2} \mathrm{O}_{2}$ 在拟 南芥抗大丽轮枝菌毒素的反应中起作用 ${ }^{[33]}$. 但有关 棉花细胞中 $\mathrm{NO}$ 和 $\mathrm{H}_{2} \mathrm{O}_{2}$ 信号的作用机制还未见报道.

谷胱甘肽S-转移酶(GST)在植物对环境条件变化 的反应中起重要作用, GST基因的表达可受许多因子 的调节. 氧化胁迫可诱导 GST 基因的表达 ${ }^{[34]}$. GST在 多种生理过程中起作用 ${ }^{[35,36]}$, 参与调节细胞程序性 死亡 ${ }^{[37]}$. 在动物细胞中, GST调节氧化胁迫过程中激 酶的活性 ${ }^{[38]}$. 最近的研究结果表明, GST可作为生物 活性配体的结合蛋白, 有些也可作为运输蛋白. 显 然, GST可能在细胞间的运输中起作用. 因此, 认为 GST在植物细胞信号转导中具有重要作用 ${ }^{[39]}$.

本研究通过观察大丽轮枝菌毒素处理引起抗病 和感病棉花品种的不同变化, 主要研究不同品种棉 花细胞 $\mathrm{NO}$ 和 $\mathrm{H}_{2} \mathrm{O}_{2}$ 产生在时间和水平上的差异, 以 及 $\mathrm{NO}$ 和 $\mathrm{H}_{2} \mathrm{O}_{2}$ 对 GST 基因的表达的影响. 结果揭示, $\mathrm{NO}$ 和 $\mathrm{H}_{2} \mathrm{O}_{2}$ 作为对大丽轮枝菌毒素反应的复杂信号 网络的一部分, 调节 GST 基因的表达, GST 基因参与 棉花细胞抗大丽轮枝菌毒素的抗性机制.

\section{1 材料与方法}

(i) 植物材料. 材料为两个对大丽轮枝菌抗性 不同的棉花(Gossypium hirsutum L.) 品种BD18(抗病 品种)和泗棉 3 号(感病品种). 棉花幼苗和愈伤组织的 培养同文献 [9]. 诱导形成的棉花愈伤组织转移到液 
体培养基中. 除琼脂外, 培养基所含的无机营养和有 机营养与愈伤组织诱导培养基相同. 实验采用培养 2 $\mathrm{d}$ 的悬浮细胞.

(ii ) 棉花悬浮细胞的处理. 悬浮细胞转移到缓 冲液(含 $50 \mathrm{mmol} / \mathrm{L} \mathrm{MES,} 75 \mathrm{mmol} / \mathrm{L}$ 蔗糖, $1 \mathrm{mmol} / \mathrm{L}$ $\mathrm{CaCl}_{2}, 1 \mathrm{mmol} / \mathrm{L} \mathrm{K}_{2} \mathrm{SO}_{4}, \mathrm{pH} 5.8$ ), 并分别附加有 25 $\mu \mathrm{g} / \mathrm{mL}$ 大丽轮枝菌毒素(VD-toxins), $0.5 \mathrm{mmol} / \mathrm{L}$ 硝普 钠(SNP, 一种 NO 供体), $0.5 \mathrm{mmol} / \mathrm{L} \mathrm{H}_{2} \mathrm{O}_{2}, 1000 \mathrm{U} / \mathrm{mL}$ 过氧化氢酶(CAT, $\mathrm{H}_{2} \mathrm{O}_{2}$ 清除酶), $0.4 \mathrm{mmol} / \mathrm{L} \mathrm{cPTIO}$ (NO 吞噬剂), $25 \mu \mathrm{g} / \mathrm{mL}$ VD-toxins 加 $0.4 \mathrm{mmol} / \mathrm{L}$ cPTIO, $25 \mu \mathrm{g} / \mathrm{mL}$ VD-toxins 加 $1000 \mathrm{U} / \mathrm{mL}$ CAT. 缓冲 液处理的细胞为对照. 在上述溶液处理的不同时间 $(0$, $1,2,4,8 \mathrm{~h}$ )收集细胞, 立即用液氮冷冻, $-20^{\circ} \mathrm{C}$ 咜存.

(iii) 大丽轮枝菌粗毒素的准备. 研究显示, 大 丽轮枝菌产生的毒素能诱导黄萎病症状 [1,10,40,41]. 本 研究从一种高致病力、非落叶型大丽轮枝菌(V229) 提取粗毒素, 大丽轮枝菌的培养方法同文献 [10]. 菌 培养液经滤纸过滤, 滤液于 $10000 \times g$ 离心 $30 \mathrm{~min}$, 去 除沉淀, 上清液于 $-20^{\circ} \mathrm{C}$ 冷冻 $24 \mathrm{~h}$, 冷冻干燥 $36 \mathrm{~h}$, 溶 于蒸馏水, 使其溶液浓度为 $0.5 \mathrm{mg} / \mathrm{mL}$. 然后, 在 $4^{\circ} \mathrm{C}$ 下用 $1 \mathrm{kD}$ 透析膜透析 $24 \mathrm{~h}$, 浓缩的溶液再次冷冻干 燥, 再将干燥后的干粉溶于蒸馏水. 溶液经 $0.45 \mu \mathrm{m}$ 孔径滤膜过滤, 滤液为毒素粗提液. 以粗提液中的蛋 白浓度代表毒素浓度, 蛋白浓度的测定采用Bradford 方法 ${ }^{[42]}$, 牛血清白蛋白(BSA, Sigma)为对照.

(iv) $\mathrm{H}_{2} \mathrm{O}_{2}$ 积累的测定. 苂光光度计法测定 $\mathrm{H}_{2} \mathrm{O}_{2}$ 产生, 在激发波长 $350 \mathrm{~nm}$, 发射波长 $460 \mathrm{~nm}$ 的条件 下, 测定莨蓉亭(scopoletin, Sigma)菼光的降低值. 取 $5 \mu \mathrm{L}$ 莨菪亭溶液 $(2 \mathrm{mmol} / \mathrm{L})$ 加入到 $1 \mathrm{~mL}$ 细胞悬浮液中, 使其终浓度为 $10 \mu \mathrm{mol} / \mathrm{L}$, 细胞于振荡器上振荡 $5 \mathrm{~min}$ 后, $10000 \times g$ 离心 $30 \mathrm{~s}$, 取 $800 \mu \mathrm{L}$ 上清液测定苂光值. $\mathrm{H}_{2} \mathrm{O}_{2}$ 的产量 $=\left(A_{\text {对照}}-A_{\text {样品 }}\right) / A_{\text {对照 }} \cdot 10(\mu \mathrm{mol} / \mathrm{L})^{[12,19]}$.

( v ) NO积累的测定. 氧合血红素(oxyhemoglobin, $\mathrm{HbO}_{2}$ ) 咜液的制备: $25 \mathrm{mg}$ 血红素(hemoglo-

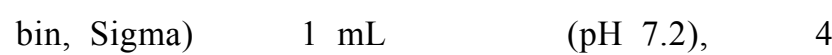
$\mathrm{mg} \mathrm{Na} \mathrm{S}_{2} \mathrm{O}_{4}$, 通入氧气或在空气流通的环境中放置 一会儿使其氧化, 血红素转化为氧合血红素 $\left(\mathrm{HbO}_{2}\right)$. 氧合血红素 $\left(\mathrm{HbO}_{2}\right)$ 溶液经Sephadex G-25 层析柱脱盐 后, 咜存于冰浴、黑暗中 ( $\mathrm{HbO}_{2}$ 必须当天制备). $\mathrm{HbO}_{2}$ 浓度可用 $415 \mathrm{~nm}$ 处的吸光值计算得出 $\varepsilon=131$ $(\mathrm{mmol} / \mathrm{L})^{-1} \cdot \mathrm{cm}^{-1}$. NO的测定: 在棉花悬浮细胞中加入 $100 \mathrm{U}$ CAT和 $100 \mathrm{U} \mathrm{SOD}$, 反应 5 min以除去ROI. 然
后, 加入 $\mathrm{HbO}_{2}$ 至终浓度为 $10 \mu \mathrm{mol} / \mathrm{L}$, 反应 $5 \mathrm{~min}$, $10000 \times g$ 离心 $30 \mathrm{~s}$, 去除细胞, 取 $0.1 \mathrm{~mL}$ 上清液在 401 和 $421 \mathrm{~nm}$ 处测定光吸收值, $\mathrm{NO}$ 的积累量 $=77$ $(\mathrm{mmol} / \mathrm{L})^{-1} \cdot \mathrm{cm}^{-1} \cdot\left[A_{401}(\mathrm{metHb})-A_{421}\left(\mathrm{HbO}_{2}\right)\right]^{[43]}$.

( vi ) 总RNA的提取和RT-PCR. 采用CTAB酸酚 法 ${ }^{[44]}$ 提取棉花细胞中的总RNA. 采用RT-PCR分析 GST 基因(登录号 CD485867)的表达, 以持家基因 histon3 (GenBank登录号: AF024716)为内标. 取 $1 \mu \mathrm{g}$ 总RNA, 由 M-MLV 反转录酶 (Promega) 和特异的 histon3 及GST引物反转录合成第 1 链cDNA, 取 $3 \mu \mathrm{L}$ cDNA溶液为模板, 进行RT-PCR分析. PCR 扩增GST 上游引物是 5'-GAACCGATGGCGAAGAACA-3', 下 游引物是 5'-GATTTTAGGCCCTGCAAAGACT-3'. PCR扩增产物的长度为 $188 \mathrm{bp}$. Histon3 上游引物是 5'-CGTAAATCTGCCCCAACCAC-3', 下游引物是 5'-CACATTGAACCTACCACTACCATC-3', PCR扩增 产物的长度为 $454 \mathrm{bp}$. PCR 反应条件是: $95^{\circ} \mathrm{C}, 3 \mathrm{~min}$, $94^{\circ} \mathrm{C}, 30 \mathrm{~s}, 57^{\circ} \mathrm{C}, 30 \mathrm{~s}, 72^{\circ} \mathrm{C}, 1 \mathrm{~min}, 24$ 个循环后 $72^{\circ} \mathrm{C}$ 延伸 $10 \mathrm{~min}$. PCR产物经 $1 \%$ 琼脂糖凝胶电泳鉴定, 用 溴化乙锭液染色. 紫外凝胶成像系统(Alpham- ager ${ }^{\mathrm{TM}}$ 2200, Alpha Innotech com)拍照, 再经ALPHA- 2200 (图像分析系统)进行电泳条带的扫描分析. 实验重复 3 次.

(vii) 统计分析. 结果数据以 3 次实验的平均值 \pm 标准差表示, 采用方差分析进行统计分析. $P<0.05$ 水平为差异显著.

\section{2 结果}

\section{1 大丽轮枝菌毒素诱导棉花悬浮细胞 $\mathrm{NO}$ 和 $\mathrm{H}_{2} \mathrm{O}_{2}$ 的积累}

为了检测大丽轮枝菌毒素是否诱导棉花细胞 NO 积累, 本研究测定了大丽轮枝菌毒素处理棉花细胞 $\mathrm{NO}$ 积累的动态变化. 结果显示, 大丽轮枝菌毒素 $(25$ $\mu \mathrm{g} / \mathrm{mL}$ )处理引起棉花细胞快速的 NO 爆发, 在毒素处 理后的 $30 \mathrm{~min}$ 出现 NO 的峰值(图 1). 在 BD18 细胞 中, $\mathrm{NO}$ 峰值升高了大约 4 倍, 随后逐渐降低; 而在泗 棉 3 号细胞中, NO 峰值仅升高了 1.5 倍.

与此相似, 我们也测定了大丽轮枝菌毒素处理 棉花细胞 $\mathrm{H}_{2} \mathrm{O}_{2}$ 产生的动态过程(图 2), 毒素处理能迅 速诱导棉花细胞 $\mathrm{H}_{2} \mathrm{O}_{2}$ 积累, 这是一种典型的活性氧 爆发过程. 大而持续的 $\mathrm{H}_{2} \mathrm{O}_{2}$ 峰值出现在毒素处理后 的 $30 \mathrm{~min}$. $\mathrm{l}$ 在 $\mathrm{BD} 18$ 细胞中, $\mathrm{H}_{2} \mathrm{O}_{2}$ 的峰值持续维持 $2 \mathrm{~h}$ 
在这一高水平上, 随后逐渐降低; 而在泗棉 3 号细胞 中, $\mathrm{H}_{2} \mathrm{O}_{2}$ 升高的峰值仅为 $\mathrm{BD} 18$ 细胞的一半, 并在这 一水平维持 $4 \mathrm{~h}$.

从以上结果可见，抗病品种中 $\mathrm{NO}$ 和 $\mathrm{H}_{2} \mathrm{O}_{2}$ 的积 累水平均明显高于感病品种.

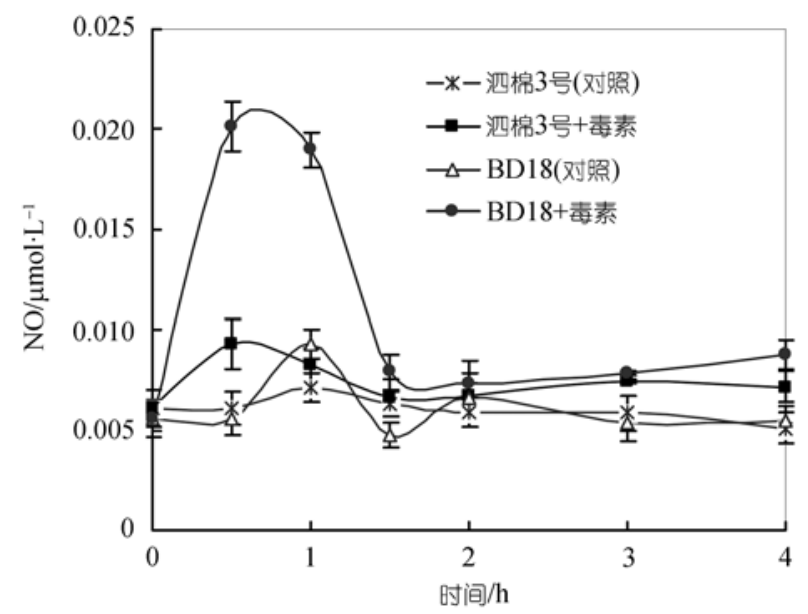

图 1 大丽轮枝菌毒素诱导棉花悬浮细胞中 NO 积累的 动态过程

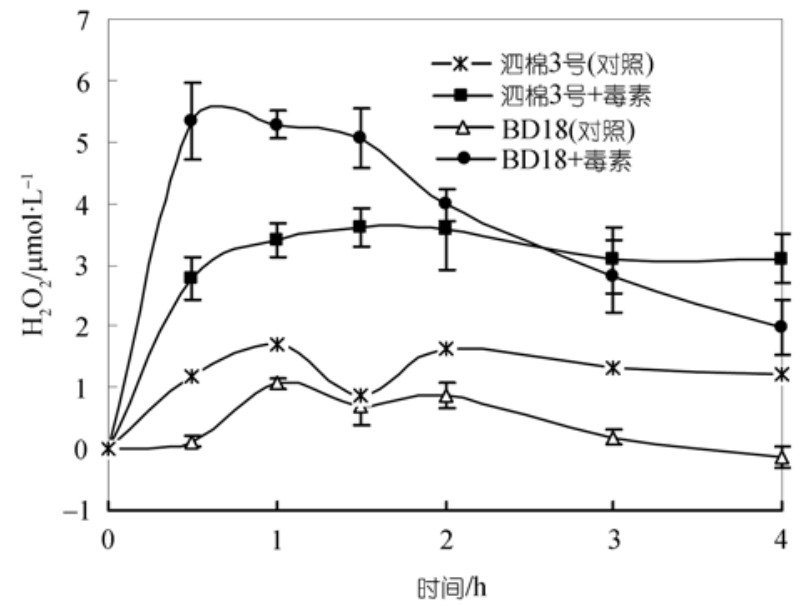

图 2 大丽轮枝菌毒素诱导棉花悬浮细胞中 $\mathrm{H}_{2} \mathrm{O}_{2}$ 积累的 动态过程

$2.2 \mathrm{SNP}$, cPTIO, $\mathrm{H}_{2} \mathrm{O}_{2}, \mathrm{CAT}$ 和大丽轮枝菌毒素对 棉花悬浮细胞 NO 和 $\mathrm{H}_{2} \mathrm{O}_{2}$ 积累的影响

为了研究 $\mathrm{NO}$ 和 $\mathrm{H}_{2} \mathrm{O}_{2}$ 在毒素诱导棉花悬浮细胞 反应中的相互作用，本研究分别测定了 CAT (1000 $\mathrm{U} / \mathrm{mL}), \mathrm{H}_{2} \mathrm{O}_{2}(0.5 \mathrm{mmol} / \mathrm{L}), \mathrm{SNP}(0.5 \mathrm{mmol} / \mathrm{L})$ 和 cPTIO $(0.4 \mathrm{mmol} / \mathrm{L})$ 对 $\mathrm{NO}$ 和 $\mathrm{H}_{2} \mathrm{O}_{2}$ 积累的影响.

在抗病品种中, 毒素和外源 $\mathrm{H}_{2} \mathrm{O}_{2}$ 明显促进 $\mathrm{NO}$ 积累, 但 CAT 抑制 NO 积累, 虽然这种抑制作用并不 显著(图 3(a)); 在感病品种中, 毒素促进 NO 积累, 尽
管促进作用并不显著, 但 $\mathrm{H}_{2} \mathrm{O}_{2}$ 和 CAT 对 NO 的积累 没有影响.

毒素、SNP 和 cPTIO 均能影响 $\mathrm{H}_{2} \mathrm{O}_{2}$ 的积累, 但 作用并不相同. 毒素和 cPTIO 明显促进 $\mathrm{H}_{2} \mathrm{O}_{2}$ 的积累, 相反, SNP 对 $\mathrm{H}_{2} \mathrm{O}_{2}$ 积累没有促进作用(图 3(b)).

结果表明, $\mathrm{H}_{2} \mathrm{O}_{2}$ 对 $\mathrm{NO}$ 积累的影响作用较小, 而 $\mathrm{NO}$ 对 $\mathrm{H}_{2} \mathrm{O}_{2}$ 的积累起重要的调节作用, $\mathrm{NO}$ 可能作为 抗氧化剂, 抑制 $\mathrm{H}_{2} \mathrm{O}_{2}$ 的产生.
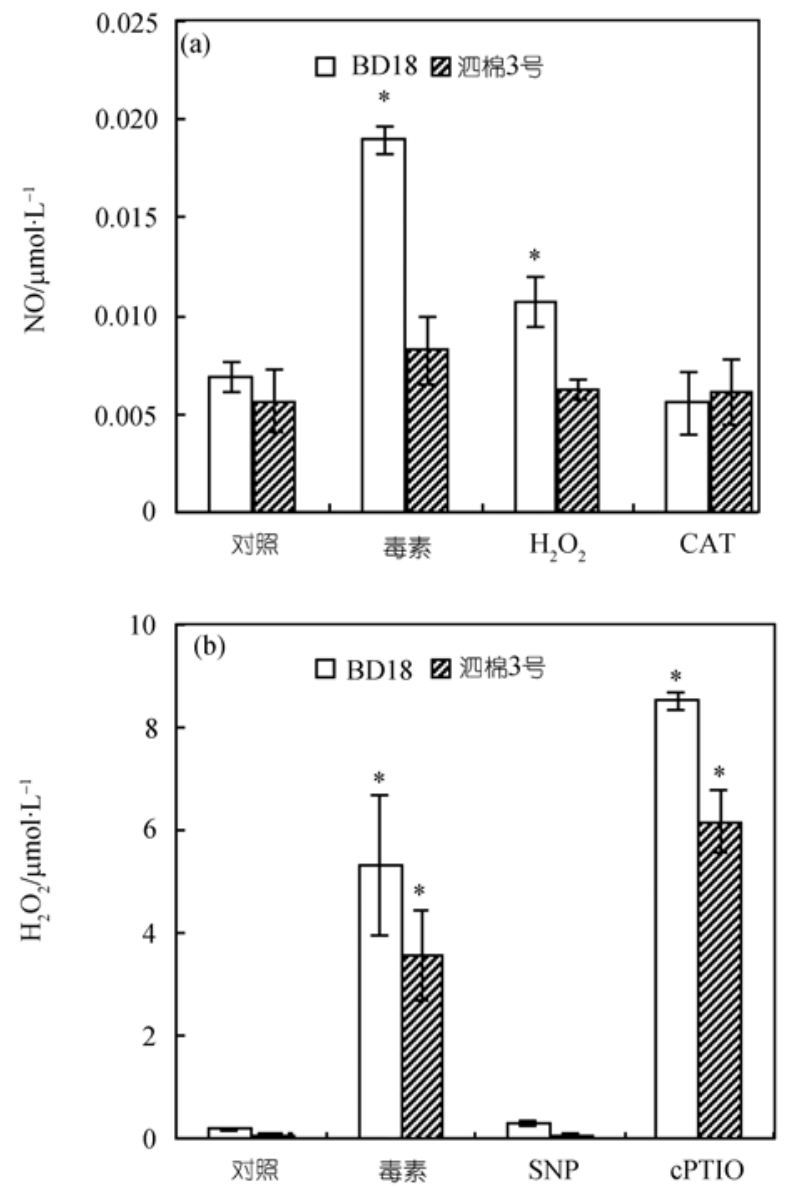

图 $3 \mathrm{SNP}, \mathrm{cPTIO}, \mathrm{H}_{2} \mathrm{O}_{2}$, CAT 和大丽轮枝菌毒素对棉花 悬浮细胞 $\mathrm{NO}$ 和 $\mathrm{H}_{2} \mathrm{O}_{2}$ 积累的影响

(a) $\mathrm{H}_{2} \mathrm{O}_{2}(0.5 \mathrm{mmol} / \mathrm{L}), \mathrm{CAT}(1000 \mathrm{U} / \mathrm{mL})$ 和大丽轮枝菌毒素 $(25$ $\mu \mathrm{g} / \mathrm{mL}$ )处理 $1 \mathrm{~h}, \mathrm{BD} 18$ 和泗棉 3 号细胞中 NO 的积累. (b) SNP $(0.5$ $\mathrm{mmol} / \mathrm{L}) 、$ cPTIO $(0.4 \mathrm{mmol} / \mathrm{L})$ 和大丽轮枝菌毒素 $(25 \mu \mathrm{g} / \mathrm{mL})$ 处理 $1 \mathrm{~h}$, $\mathrm{BD} 18$ 和泗棉 3 号细胞中 $\mathrm{H}_{2} \mathrm{O}_{2}$ 的积累. *示在 $5 \%$ 水平有显著差异

$2.3 \mathrm{H}_{2} \mathrm{O}_{2}, \mathrm{NO}$ 和大丽轮枝菌毒素对棉花悬浮细胞中 $G S T$ 基因表达的影响

通过检测 GST 基因的表达以阐明大丽轮枝菌毒 素在转录水平对防卫反应基因的调控作用. 大丽轮 枝菌毒素处理迅速诱导 GST-mRNA 的增加，且这种 
增加在抗病品种比感病品种更迅速(图 4). 在 BD18 细胞中, 大丽轮枝菌毒素处理 $2 \mathrm{~h}$, GST mRNA 明显 增加，与对照相比, GST 基因表达水平增加了 $71.5 \%$; 毒素处理 $4 \mathrm{~h}, G S T$ mRNA 增加达到最高水平, 为对 照的 $185 \%$. 在泗棉 3 号细胞中, GST mRNA 明显增加 出现在大丽轮枝菌毒素处理 $4 \mathrm{~h}$, 但仅为对照的 $69.2 \%$.

(a)
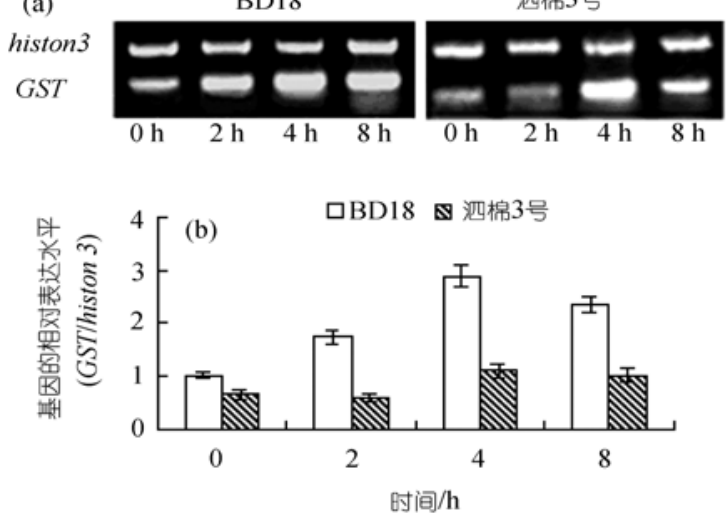

图 4 RT-PCR 分析大丽轮枝菌毒素处理不同抗病品种 棉花细胞对 GST 基因表达的影响

(a) 大丽轮枝菌毒素处理不同时间棉花细胞 GST 基因的表达; (b) 大 丽轮枝菌毒素处理不同时间棉花细胞 GST 基因的相对表达水平

我们也测定了外源 $\mathrm{H}_{2} \mathrm{O}_{2}(0.5 \mathrm{mmol} / \mathrm{L})$ 和 $\mathrm{SNP}$ $(0.5 \mathrm{mmol} / \mathrm{L})$ 对 GST mRNA 表达的影响. 如图 5 所示, 外源 $\mathrm{H}_{2} \mathrm{O}_{2}$ 能促进 GST mRNA 的表达, 促进作用在抗 病品种更强. $\mathrm{H}_{2} \mathrm{O}_{2}$ 处理 $1 \mathrm{~h}, \mathrm{BD} 18$ 细胞中的 GSTmRNA 明显增加; 在泗棉 3 号细胞中, GST-mRNA 的 增加出现在 $\mathrm{H}_{2} \mathrm{O}_{2}$ 处理 $2 \mathrm{~h}$, 分别增加 $47.7 \%$ 和 $61.3 \%$. 两个品种中 GST-mRNA 的增加均持续到 $\mathrm{H}_{2} \mathrm{O}_{2}$ 处理 4 h. 结果表明, $\mathrm{H}_{2} \mathrm{O}_{2}$ 促进 GST mRNA 的表达.

与之相比, SNP $(0.5 \mathrm{mmol} / \mathrm{L})$ 对 GST mRNA 增加 的促进作用较小, 作用的时间更短, 如图 6 所示. 在 抗病品种中, GST mRNA增加的最大值出现在 SNP处 理后 $1 \mathrm{~h}$, 感病品种出现在 SNP 处理 $2 \mathrm{~h}$, 与对照相比, 分别增加 $29.6 \%$ 和 $31.9 \%$; 处理 $4 \mathrm{~h}$, GST mRNA 降低 到原初水平, 表明 NO也促进 GST 基因的表达. 由于 前一结果已经证明, SNP 在此浓度下未能诱导 $\mathrm{H}_{2} \mathrm{O}_{2}$ 的明显积累, 因此, 很可能由 NO 促进 GST 表达的信 号途径并不依赖于 $\mathrm{H}_{2} \mathrm{O}_{2}$. 上述结果表明, $\mathrm{H}_{2} \mathrm{O}_{2}$ 促进 $G S T$ 基因表达作用比 NO 的更强.
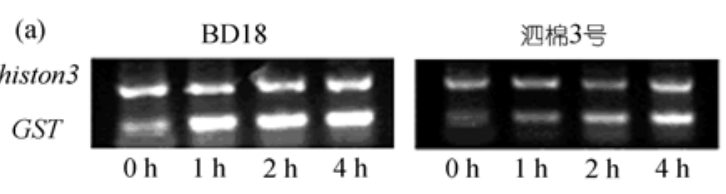

口BD18 沉棉3ㅁ丂

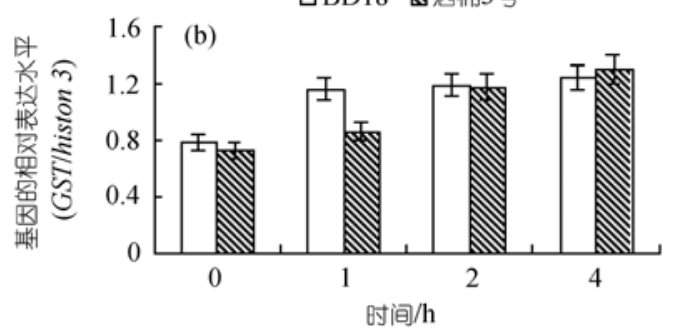

图 5 RT-PCR 分析 $\mathrm{H}_{2} \mathrm{O}_{2}$ 处理不同抗病品种棉花细胞对 GST 基因表达的影响

(a) $\mathrm{H}_{2} \mathrm{O}_{2}(0.5 \mathrm{mmol} / \mathrm{L})$ 处理不同时间棉花细胞 GST 基因的表达; (b) $\mathrm{H}_{2} \mathrm{O}_{2}$ 处理不同时间棉花细胞 GST 基因的相对表达水平

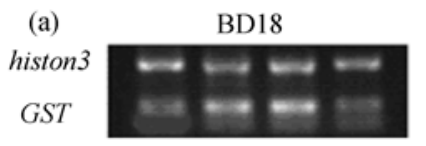

$\begin{array}{llll}0 \mathrm{~h} & 1 \mathrm{~h} & 2 \mathrm{~h} & 4 \mathrm{~h}\end{array}$

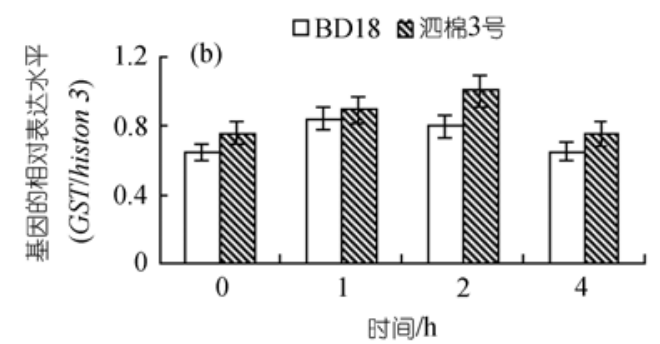

图 6 RT-PCR 分析 SNP 处理不同抗病品种棉花细胞对 $G S T$ 基因表达的影响

(a) SNP $(0.5 \mathrm{mmol} / \mathrm{L})$ 处理不同时间棉花细胞 GST 基因的表达; (b) SNP 处理不同时间棉花细胞 GST 基因的相对表达水平

为进一步研究内源 $\mathrm{H}_{2} \mathrm{O}_{2}$ 和 $\mathrm{NO}$ 在大丽轮枝菌毒 素诱导 GST 基因表达中的作用, 用大丽轮枝菌毒素 与 CAT $(1000 \mathrm{U} / \mathrm{mL})$ 或 cPTIO $(0.4 \mathrm{mmol} / \mathrm{L})$ 同时处理 棉花细胞, 检测 GST 基因的表达. 结果如图 7 所示, 当毒素与 CAT 同时处理抗病和感病品种棉花细胞, GST mRNA 的积累比单独毒素处理时分别降低了 $59.4 \%$ 和 $31.8 \%$. 当毒素与 cPTIO 同时处理, GST mRNA 的积累比单独毒素处理时分别降低了 $49.6 \%$ 和 $17.8 \%$. 可见, CAT 抑制 GST mRNA 表达的作用比 cPTIO 的更明显. 这也表明, $\mathrm{H}_{2} \mathrm{O}_{2}$ 在促进 GST 基因表 达中起主要作用. 


$$
\text { (a) }
$$

BD18
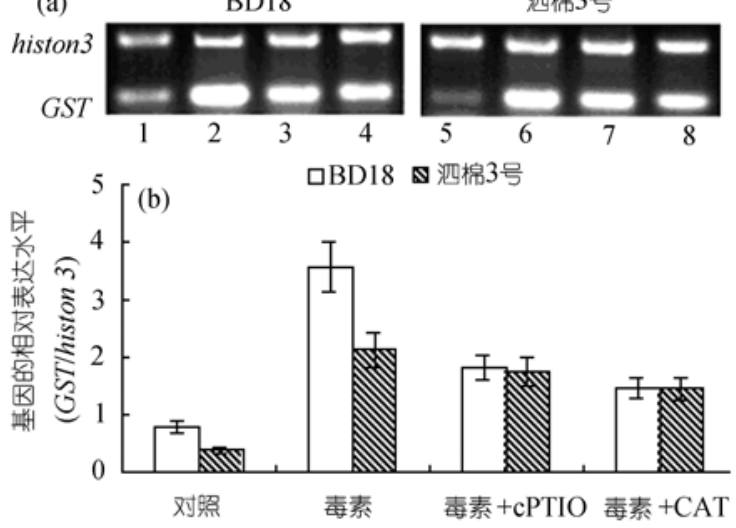

图 7 RT-PCR 分析大丽轮枝菌毒素与 cPTIO 和 CAT 同时 处理不同抗病品种棉花细胞对 GST 基因表达的影响

(a) 毒素、毒素与 cPTIO 和毒素与 CAT 同时处理棉花细胞 $4 \mathrm{~h}$ 后 GST 基因的表达水平. 1 , 对照; 2 , 毒素处理; 3 , 毒素与 $\mathrm{cPTIO}$ 同时处理; 4, 毒素与 CAT 同时处理; 5 , 对照; 6 , 毒素处理; 7, 毒素与 cPTIO 同时处 理; 8, 毒素与 CAT 同时处理. (b) 不同处理条件下不同抗病品种棉花 细胞 GST 基因的相对表达水平

\section{3 讨论}

深入了解植物抗大丽轮枝菌防卫反应的分子机 制是有效控制黄萎病发生的主要先决条件. 虽然已 经证明, $\mathrm{NO}$ 和 $\mathrm{H}_{2} \mathrm{O}_{2}$ 在诱导植物防卫反应中起关键作 用, 这些信号分子参与诱导许多防卫相关基因的表 达 ${ }^{[12,45 \sim 51]}$, 但对 $\mathrm{NO}$ 和 $\mathrm{H}_{2} \mathrm{O}_{2}$ 参与棉花抗大丽轮枝菌或 大丽轮枝菌毒素防卫反应的分子机制了解甚少.

在本研究中, 我们观察到大丽轮枝菌毒素能迅 速诱导棉花细胞 $\mathrm{NO}$ 和 $\mathrm{H}_{2} \mathrm{O}_{2}$ 爆发, 这种爆发在抗性 品种中更强烈, 而且, 棉花细胞中 $\mathrm{NO}$ 和 $\mathrm{H}_{2} \mathrm{O}_{2}$ 的产生 是平行的. 这表明 $\mathrm{NO}$ 和 $\mathrm{H}_{2} \mathrm{O}_{2}$ 作为信号分子, 可以协 同或单独作用，参与棉花细胞抗大丽轮枝菌毒素的 抗性反应. 这也就是说, $\mathrm{NO}$ 和 $\mathrm{H}_{2} \mathrm{O}_{2}$ 在棉花细胞抗大 丽轮枝菌毒素的抗性反应中起重要作用.

已有报道, NO与ROS协同作用启动HR反应中的 细胞死亡 ${ }^{[19,52]}$, 其可能的机制是NO能够确保维持高 的、持续的 $\mathrm{H}_{2} \mathrm{O}_{2}$ 水平, 这是启动 $\mathrm{HR}$ 反应的必要因子 [27,32]. 然而, 另有报道, NO与ROS并不协同作用诱导 拟南芥悬浮细胞的细胞死亡, NO诱导的细胞死亡不 依赖ROS ${ }^{[53]}$. Beligni和Lamattina ${ }^{[54,55]}$ 证明, NO可作为 抗氧化剂, 清除ROS, 抑制 $\mathrm{H}_{2} \mathrm{O}_{2}$ 信号途 径, 引起细 胞死亡. 也有研究证明, $\mathrm{NO}$ 和 $\mathrm{H}_{2} \mathrm{O}_{2}$ 在活化防卫反应 的转录过程中具有互补功能 ${ }^{[29]}$. 最近, 在 Colletotrichum coccodes与番茄互作反应中发现, $\mathrm{H}_{2} \mathrm{O}_{2}$
介导NO调控的防卫反应 ${ }^{[51]}$.

本研究结果表明, 在两个棉花品种中, 单独NO 供体抑制 $\mathrm{H}_{2} \mathrm{O}_{2}$ 的积累, 表明在棉花细胞中NO可能作 为抗氧化剂, 抑制 $\mathrm{H}_{2} \mathrm{O}_{2}$ 的积累. 为证实这一假设, 用 $\mathrm{NO}$ 吞噬剂cPTIO处理棉花细胞, 结果显示, $\mathrm{H}_{2} \mathrm{O}_{2}$ 积累 明显增加，表明该浓度的 $\mathrm{NO}$ 具有抗氧化效应，起保 护细胞免受氧化胁迫的作用. 结果与以前的报道相 一致 $[54,55]$. 在棉花细胞抗大丽轮枝菌毒素抗性反应 中, $\mathrm{NO}$ 的可能功能是抑制氧化机制, 确保 $\mathrm{H}_{2} \mathrm{O}_{2}$ 的低 水平. 这一结果也与 $\mathrm{NO}$ 调节 $\mathrm{H}_{2} \mathrm{O}_{2}$ 的积累, 降低其在 防卫相关基因表达效应 ${ }^{[56 \sim 58]}$ 的结论相符.

在拟南芥和大豆中已经证实, $\mathrm{H}_{2} \mathrm{O}_{2}$ 诱导GST基 因的表达 $[12,14]$. 枯萎菌(Fusarium oxysporum f. sp. vasinfectum)侵染棉花根部和下胚轴，增强了 GST同 源基因的表达 ${ }^{[59]}$. 本研究结果证实, 大丽轮枝菌毒 素诱导棉花悬浮细胞中 GST 基因表达增加. 与感病品 种相比，在抗病品种中 GST基因的表达更强、更迅速. 这说明棉花细胞对大丽轮枝菌毒素抗性反应的不同 与其 GST基因的表达有关. 这一结果证实了我们的假 设, GST在对大丽轮枝菌毒素的抗性反应中起重要作 用. 换言之, 在棉花悬浮细胞中, GST基因参与抗大 丽轮枝菌毒素的抗性机制. $\mathrm{H}_{2} \mathrm{O}_{2}$ 信号在大丽轮枝菌 毒素作用的下游起作用, 且 $\mathrm{H}_{2} \mathrm{O}_{2}$ 是诱导GST基因表 达的主要信号分子. NO也参与诱导 GST 基因表达的 信号途径, 但它的作用较小, 并且不依赖于 $\mathrm{H}_{2} \mathrm{O}_{2}$. 与 我们的结果不同的是: 在拟南芥中, $\mathrm{NO}$ 依赖于 $\mathrm{H}_{2} \mathrm{O}_{2}$ 诱导GST 基因的表达 ${ }^{[26,60]}$, 而在马铃薯中, NO不参 与cryptogein诱导的GST基因的表达 [61]. 这样, NO, $\mathrm{H}_{2} \mathrm{O}_{2}$ 和 $G S T$ 基因之间的相关性可能与植物与激发子 或病原菌间的相互反应有关.

本研究首次在棉花与大丽轮枝菌毒素相互作用 中证实, NO 和 $\mathrm{H}_{2} \mathrm{O}_{2}$ 作为复杂信号网络的一部分, 两 者协同或单独作用诱导棉花细胞抗大丽轮枝菌毒素 的抗性反应，GST 基因参与了这一抗性机制. NO 对 $G S T$ 基因表达的调控不依赖 $\mathrm{H}_{2} \mathrm{O}_{2}, \mathrm{H}_{2} \mathrm{O}_{2}$ 诱导抗性反 应的作用更强. 有关 $\mathrm{NO}$ 和 $\mathrm{H}_{2} \mathrm{O}_{2}$ 在调控抗大丽轮枝 菌毒素抗性反应中作用机制的实质有待进一步深入 研究.

致谢 感谢 Yiji Xia 博士(Donald Danforth Plant Science Center, USA)提供 $\mathrm{H}_{2} \mathrm{O}_{2}$ 测定方法. 


\section{参考文献}

1 Fradin E F, Thomma B P H J. Physiology and molecular aspects of Verticillium wilt diseases caused by $V$. dahliae and V. albo-atrum. Mol Plant Pathol, 2006, 7: 71-86 [DOI]

2 Diwan N, Fluhr R, Eshed Y, et al. Mapping of Ve in tomato: A gene conferring resistance to the broad-spectrum pathogen, Verticillium dahliae race 1. Theoret Appl Genet, 1999, 98: 315-319 [DOI]

3 Hill M K, Lyon K J, Lyon B R. Identification of disease response genes expressed in Gossypium hirsutum upon infection with the wilt pathogen Verticilliium dahliae. Plant Mol Biol, 1999, 40: 289 -296 [DOI]

4 Cui Y, Bell A A, Joost O, et al. Expression of potential defense response genes in cotton. Physiol Mol Plant Pathol, 2000, 56: 2531 [DOI]

5 Kawchuk L M, Hachey J, Lynch D R, et al. Tomato ve disease resistance genes encode cell surface-like receptors. Proc Natl Acad Sci USA, 2001, 98: 6511-6515[DOI]

6 McFadden H G, Chapple R, Fayter R, et al. Expression of pathogenesis- related genes in cotton stems in response to infection by Verticillium dahliae. Physiol Mol Plant Pathol, 2001, 58: 119132 [DOI]

7 Dubery I A, Slater V. Induced defence responses in cotton leaf disks by elicitors from Verticillium dahliae. Phytochemistry, 1997, 44: 1429-1434 [DOI]

8 Smit F, Dubery I A. Cell wall reinforcement in cotton hypocotyls in response to a Verticillium dahliae elicitor. Phytochemistry, 1997, 44: 811-815 [DOI]

9 Li Y Z, Zheng X H, Tang H L, et al. Increase of $\beta$-1,3-glucanase and chitinase activities in cotton callus cells treated by salicylic acid and toxin of Verticillium dahliae Kleb. Acta Bot Sin, 2003, 45: $802-808$

10 Zhen $\mathrm{X} \mathrm{H}$, Li Y Z. Ultrastructural changes and location of $\beta$-1,3-glucanase in resistant and susceptible cotton callus cells in response to treatment with toxin of Verticillium dahliae and salicylic acid. J Plant Physiol, 2004, 161: 1367-1377 [DOI]

11 Yuan H Y, Yao L L, Jia Z Q, et al. Verticillium dahliae toxin induced alterations of cytoskeletons and nucleoli in Arabidopsis thaliana suspension cells. Protoplasma, 2006, 229: 75-82 [DOI]

12 Levine A, Tenhaken R, Dixon R, et al. $\mathrm{H}_{2} \mathrm{O}_{2}$ from the oxidative burst orchestrates the plant hypersensitive disease resistance response. Cell, 1994, 79: 583-593 [DOI]

13 Lamb C, Dixon R A. The oxidative burst in plant disease resistance. Annu Rev Plant Physiol Plant Mol Biol, 1997, 48: 251-275[DOI]

14 Desikan R, Reynolds A, Hancock J T, et al. Harpin and hydrogen peroxide both initiate programmed cell death but have differential effects on defence gene expression in Arabidopsis suspension cultures. Biochem J, 1998, 330: 115-120

15 Desikan R, Neill S J, Hancock J T. Hydrogen peroxide-induced gene expression in Arabiopsis thaliana. Free Radical Biol Med, 2000, 28: 773-778[DOI]

16 Hancock J T, Desikan R, Neill S T. Hydrogen peroxide and nitric oxide in plant defence: Revealing potential targets for oxidative stress tolerance? Biofactors, 2001, 15: 99-101

17 Breusegem F V, Dat J F. Reactive oxygen species in plant cell death. Plant Physiol, 2006, 141: 384-390 [DOI]

18 Desikan R, A-H-Mackerness S, Hancock J T, et al. Regulation of the Arabiopsis transcriptome by oxidative stress. Plant Physiol, 2001, 127: 159-172 [DOI]

19 Delledonne M, Xia Y, Dixon R A, et al. Nitric oxide functions as a signal in plant disease resistance. Nature, 1998, 394: 585-588 [DOI]

20 Durner J, Wendehenne D, Klessig D F. Defense gene induction in tobacco by nitric oxide, cyclic GMP, and cyclic ADP-ribose. Proc Natl Acad Sci USA, 1998, 95: 10328 - 10333[DOI]

21 Klessig D F, Durner J, Noad R, et al. Nitric oxide and salicylic acid signaling in plant defense. Proc Natl Acad Sci USA, 2000, 97: 8849-8855[DOI]

22 Huang X, Kiefer E, von Rad U, et al. Nitric oxide burst and nitric oxide-dependent gene induction in plants. Plant Physiol Biochem, 2002, 40: 625-631[DOI]

23 Zeier J, Delledonne M, Mishina T, et al. Genetic elucidation of nitric oxide signaling in incompatible plant-pathogen interactions. Plant Physiol, 2004, 136: 2875-2886[DOI]

24 Delledonne M. NO news is good news for plants. Curr Opin Plant Biol, 2005, 8: 390-396[DOI]

25 Lamotte O, Courtois C, Barnavon L, et al. Nitric oxide in plants: The biosynthesis and cell signaling properties of a fascinating molecule. Planta, 2005, 221: 1-4[DOI]

26 Grün S, Lindermayr C, Sell S, et al. Nitric oxide and gene regulation in plant. J Exp Bot, 2006, 57: 507-516[DOI]

27 Delledonne M, Zeier J, Marocco A, et al. Signal interactions between nitric oxide and reactive oxygen intermediates in the plant hypersensitive disease resistance response. Proc Natl Acad Sci USA, 2001, 98: 13454-13459[DOI]

28 Murgia I, Tarantino D, Vannini C, et al. Arabidopsis thaliana plants overexpressing thylakoidal ascorbate peroxidase show increased resistance to paraquat-induced photooxidative stress and to nitric oxide-induced cell death. Plant J, 2004, 38: 940-953[DOI]

29 Polverari A, Molesini B, Pezzotti M, et al. Nitric oxide-mediated transcriptional changes in Arabidopsis thaliana. Mol Plant-Micro Inter, 2003, 16: 1094-1105

30 Mur L A J, Carver T L W, Prats E. NO way to live; the various roles of nitric oxide in plant-pathogen interactions. J Exp Bot, 2006, 57: 489-505[DOI]

31 Prats E, Mur L A J, Sanderson R, et al. Nitric oxide contributes both papilla-based resistance and the hypersensitive response in barley attacked by Blumeria graminis f. sp. hordei. Mol Plant Pathol, 2005, 6: 65-78[DOI]

32 Zago E, Morsa S, Dat J F, et al. Nitric oxide- and hydrogen peroxide-responsive gene regulation during cell death induction in tobacco. Plant Physiol, 2006, 141: 404-411[DOI]

33 李双石, 李颖章. 大丽轮枝菌毒素与拟南芥互作反应中 $\mathrm{SA}, \mathrm{NO}$ 和 $\mathrm{H}_{2} \mathrm{O}_{2}$ 信号的相关性. 实验生物学报, 2004, 37: 321-328

34 McGonigle B, Keeler S J, Lau S C, et al. A genomics approach to the comprehensive analysis of the glutathione S-transferase gene family in soybean and maize. Plant Physiol, 2000, 124: 1105$1120[\mathrm{DOI}]$

35 Marra K A. The functions and regulation of glutathione S-transferases in plants. Ánnu Rev Plant Physiol Plant Mol Biol, 1996, 47: 
$127-158[\mathrm{DOI}]$

36 Arakawa Y, Masaoka Y, Sakai J, et al. An alfalfa gene similar to glutathione S-transferase is induced in root by iron deficiency. Soil Sci Plant Nutr, 2002, 48: 111-116

37 Dixon D P, Lapthorn A, Edwards R. Plant glutathione transferases. Genome Biol, 2002, 3: 3004.1-3004.10[DOI]

38 Yin Z M, Ivanov V N, Habelhah H, et al. Glutathione S-transferase elicits protection against $\mathrm{H}_{2} \mathrm{O}_{2}$-induced cell death via coordinated regulation of stress kinases. Cancer Res, 2000, 60: 4053-4057

39 Foyer C H, Noctor G. Oxidant and antioxidant signaling in plants: A re-evaluation of the concept of oxidative stress in a physiological context. Plant Cell Environ, 2005, 28: 1056-1071[DOI]

40 Chu Z Q, Jia J W, Zhou X J, et al. Isolation of glycoproteins from Verticillium dahliae and their phytotoxicity. Acta Bot Sin, 1999, 41: $972-976$

41 Jiang J, Fan L W, Wu W H. Evidences for involvement of endogenous cAMP in Arabidopsis defense responses to Verticillium toxins. Cell Res, 2005, 15: 585-592[DOI]

42 Bradford M N. A rapid and sensitive method for the quantitation of microgram quantities of protein using the principle of protein-dye binding. Anal Biochem, 1976, 72: 248-254

43 Murphy M E, Noack E. Nitric oxide assay using hemoglobin method. Meth Enzymol, 1994, 233: 241-250

44 蒋健雄, 张天真. 利用 CTAB-酸酚法提取棉花组织总 RNA. 棉 花学报, 2003, 15: 166-167

45 Wu G, Shortt B J, Lawrence E B, et al. Activation of host defense mechanisms by elevated production of $\mathrm{H}_{2} \mathrm{O}_{2}$ in transgenic plants. Plant Physiol, 1997, 115: 427-435

46 Chamnongpol S, Willekens H, Moeder W, et al. Defense activation and enhanced pathogen tolerance induced by $\mathrm{H}_{2} \mathrm{O}_{2}$ in transgenic tobacco. Proc Natl Acad Sci USA, 1998, 95: 5818-5823[DOI]

47 van Camp W, van Montagu M, Inzé D. $\mathrm{H}_{2} \mathrm{O}_{2}$ and NO: Redox signals in disease resistance. Trends Plant Sci, 1998, 3: 330334 [DOI]

48 Shiloh M U, Nathan C F. Reactive nitrogen intermediates and the pathogenesis of Salmonella and Mycobacteria. Curr Opin Microbiol, 2000, 3: 35-42[DOI]

49 Borden S, Higgins V J. Hydrogen peroxide plays a critical role in the defence response of tomato to Cladosporium fulvum. Physiol
Mol Plant Pathol, 2002, 61: 227-236[DOI]

50 Neill S J, Desikan R, Clarke A, et al. Hydrogen peroxide and nitric oxide as signal molecules in plants. J Exp Bot, 2002, 53: 1237$1247[\mathrm{DOI}]$

51 Wang J, Higgins V. Nitric oxide modulates $\mathrm{H}_{2} \mathrm{O}_{2}$-mediated defenses in the Colletotrichum coccodes-tomato interaction. Physiol Mol Plant Pathol, 2006, 67: 131-137[DOI]

52 de Pinto M C, Tommasi F, Gara L D. Changes in the antioxidant systems as part of the signaling pathway responsible for the programmed cell death activated by nitric oxide and reactive oxygen species in tobacco bright-yellow 2 cells. Plant Physiol, 2002, 130: 698-708[DOI]

53 Clarke A, Desikan R, Hurst R D, et al. NO way back: Nitric oxide and programmed cell death in Arabidopsis thaliana suspension cultures. Plant J, 2000, 24: 667-677[DOI]

54 Beligni M V, Lamattina L. Nitric oxide counteracts cytotoxic processes mediated by reactive oxygen species in plant tissues. Planta, 1999, 208: 337-344[DOI]

55 Beligni M V, Lamattina L. Nitric oxide protects against cellular damage produced by methylviologen herbicides in potato plants. Nitric Oxide, 1999, 3: 199-208[DOI]

56 Pedroso M C, Magalhaes J R, Durzan D. Nitric oxide induces cell death in Taxus cells. Plant Sci, 2000, 157: 173-180[DOI]

57 Orozco-Cárdenas M L, Ryan C A. Nitric oxide negatively modulates wound signaling in tomato plants. Plant Physiol, 2002, 130: 487-493[DOI]

58 Tada Y, Mori T, Shinogi T, et al. Nitric oxide and reactive oxygen species do not elicit hypersensitive cell death but induce apoptosis in the adjacent cells during the defense response of oat. Mol Plant-Micro Inter, 2004, 17: 245-253

59 Dowd C, Wilson I W, Mcfadden H. Gene expression profile changes in cotton root and hypocotyls tissues in response to infection with Fusarium oxysporum f. sp. vasinfectum. Mol Plant-Micro Inter, 2004, 17: 654-667

60 Zaninotto F, Camera S L, Polverari A, et al. Cross talk between reactive nitrogen and oxygen species during the hypersensitive disease resistance response. Plant Physiol, 2006, 141: 379-383[DOI]

61 Lamotte O, Gould K, Lecourieux D, et al. Analysis of nitric oxide signaling functions in tobacco cells challenged by the elicitor cryptogein. Plant Physiol, 2004, 135: 516-528[DOI] 